\title{
Verlängert der Anblick praller Brüste Männerleben?
}

- Starrt ein Mann einer Frau ausgiebig und tief in den Ausschnitt, muss dies kein Zeichen ungehobelten Flegeltums sein. Bei besagtem Mann könnte es sich auch um einen gesundheitsbewussten Zeitgenossen handeln, der gerade etwas für seine Langlebigkeit tut.

Der Herr, von dem wir hier reden, ist sicher viel im Internet unterwegs und verkehrt dort - nein, nicht was Sie jetzt denken. Auf Gesundheitsseiten ist er unterwegs. Das sind wir berufsbedingt auch. Und wer im Internet nach Gesundheitsthemen sucht, stößt früher oder später auf eine bahnbrechende Studie aus Frankfurt a. M.

Unter der Leitung der Gerontologin Dr. Karen Weatherby wurden 200 gesunde Männer angehalten, entweder täglich einer Frau in den Ausschnitt zu linsen (zehn Minuten pro Tag) oder verschämt wegzugucken, sollten weibliche Rundungen in ihr Blickfeld geraten. Die Studienteilnehmer hielten dies fünf Jahre lang durch. Hingucker wurden mit einem niedrigeren Blutdruck, einem langsameren Ruhepuls und weniger kardiovaskulären Malaisen belohnt. Männer, die sich täglich zehn Minuten lang weibliche Brüste vor Augen führten, lebten im Schnitt fünf Jahre länger. Ältere
Männer sollten als Anschauungsmaterial größere Brüste wählen, so der Rat des Weatherby-Teams. Die Studie solle demnächst im "New England Journal of Medicine" erscheinen, meldet die indische Gesundheitsseite "the medGuru".

Da sind die Medgurus - und nicht nur die - leider einer Falschmeldung aufgesessen. Die Studie ist längst erschienen, in „Weekly World News". Das ist ein Blatt, das kaum jemals eine wahre Meldung veröffentlicht hat. Das ist keine Rufschädigung, sondern in diesem Fall Verlagsprogramm.

Die Studie hat sich von der bekanntermaßen unglaubwürdigen Quelle gelöst und führt jetzt im Internet ein Eigenleben. Auch Dr. Karen Weatherby finden Sie im Internet. Geben Sie doch mal den Namen in die Bildersuche von Google ein. Sie finden jede Menge Anschauungsmaterial. Aber ob das wirklich den Blutdruck senkt?

R. Manhart .

\section{NEUE THERAPIEOPTION}

\section{Mit Peginterferon alpha gegen Hepatitis D}

- Gegen die aggressivste Form der Virushepatitis scheint ein therapeutischer Durchbruch gelungen: Bei knapp einem Viertel von Hepatitis-D-Patienten war nach einer 48-wöchigen Therapie mit Peginterferon alpha-2a keine virusspezifische RNA mehr nachweisbar. Diesen Erfolg melden Wissenschaftler der Medizinischen Hochschule Hannover nach Auswertung der bislang größten internationalen Studie zur Behandlung der Hepatitis D. 90 Patienten wurden in drei Gruppen mit Peginterferon alpha-2a (180 $\mu \mathrm{g} /$ Woche), mit dem Virostatikum Adefovir (10 mg/Tag) oder einer Kombination aus beiden behandelt. Auch 24 Wochen nach Therapieende war bei 28\% der Patienten mit Kombinationstherapie, aber auch mit Peginterferon-alphaMonotherapie der Test auf HDV-RNA negativ. Zudem reduzierte sich im Serum von zehn Probanden der Kombinationsgruppe sowie von zwei Teilnehmern der Peginterferon-alpha-Gruppe das Oberflächenantigen des Hepatitis B-Virus (HBs-Antigen) deutlich, in der Adefovir-Gruppe dagegen bei keinem Patienten. Dies gilt als weiterer Erfolg, denn die Hepatitis D tritt nur als Koinfektion einer Hepatitis B auf, da das Hepatitis-D-Virus die Hülle des Hepatitis-B-Vi- rus benötigt. Mit der Kombinationsbehandlung könnte sich nun erstmals eine Standardtherapie etablieren.

N Engl J Med 2011; 364:322-331 Jan 27, 2011

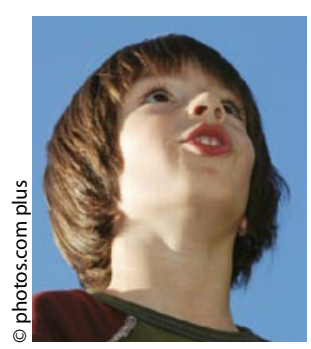

Gute Zukunft?

\section{VERHALTENSAUFFÄLLIG}

\section{Erst Problemkind, später Outlaw?}

- Hyperaktivität, Konzentrationsschwäche, impulsives Verhalten: Kinder mit solchen Verhaltens-

auffälligkeiten haben es auch als Erwachsene schwer. Das belegt eine Studie, die etwa tausend Kinder in Neuseeland und rund 500 Zwillingspaare in Großbritannien über mehrere Jahrzehnte verfolgte.

Die Autoren um Terrie Moffitt von der Duke-Universität, North Carolina registrierten bei verhaltensauffälligen Kindern im Erwachsenenalter vermehrt Alkoholund Drogenkonsum, ungewollte Schwangerschaften, Konflikte mit dem Gesetz, Finanzprobleme, Übergewicht, Geschlechtskrankheiten sowie hohen Blutdruck. Probleme bei Kindern bedeuteten aber keinesfalls automatisch eine düstere Lebensperspektive. Die Studie konnte auch zeigen, dass sich Selbstkontrolle erlernen lässt. Ändern die Kinder beim Älterwerden ihr Verhalten, haben sie auch weniger Probleme als Erwachsene.

JM =

www.pnas.org/lookup/suppl/doi:10.1073/ pnas.1010076108/-/DCSupplemental 